\title{
The Kanehira-Hatusima 1940 Collection of New Guinea Plants. I.
}

By

\section{Ryôzô Kanehira.}

Received May 5, 1941.

In 1940 I fortunately had an opportunity of botanizing in Netherlands New Guinea. Accompanied by Mr. S. Hatusima, lecturer in dendrology at Kyusyu Imperial University, we proceeded to Java with the objective of visiting the Botanical Gardens at Buitenzorg to confer with botanists there, familiarize ourselves with essential literature, and at the same time to arrange for advice and assistance regarding our proposed trip to New Guinea. We arrived at Manokwari on February 20 and three days later proceeded to Nabire which is situated at the head of Geelvink Bay. This settlement is located at the mouth of the Nabire River which flows into the bay at that point. There the Nanyô Kôhatu Kaisya (South Seas Developing Company) maintains a depot for the receipt of dammar. This product is transported from Dallmann which is situated inland about $50 \mathrm{~km}$. south of Nabire at an altitude of 500-800 m., where the company has a dammar concession. A botanical trip was made along the trail to Dallmann and we returned in canoes on the Boemi River. This region is for the most part an undulating plain covered with dense primary forests, and the banks of both the Nabire and Boemi Rivers are usually flooded in the rainy seasons. Sixteen days were devoted to this field work.

A second objective was to botanize in the vicinity of Lake Angi. We arrived at Momi on March 19. This is a village about 40 miles south of Manokwari, and here the Developing Company maintains plantations for jute and cotton. After spending two weeks botanizing in the vecinity of Momi, we left for Lake Angi on April 4, escorted by a military guard and accompanied by the Controller Mr. Muelder. Four days were used for the trip in and out and we spent four days in the vicinity of the Lake.

During the time we spent in New Guinea, about 2,851 numbers were collected with the following result.

In accordance with our agreement with the Netherlands East Indies authorities a nearly complete set of duplicate specimens has been sent to the herbarium of the Buitenzorg Botanical Garden, and an additional set of duplicates is also sent to the Arnold-Arboretum of Harvard University. Special groups have been studied by the following botanists: Dr. H. Iто, 


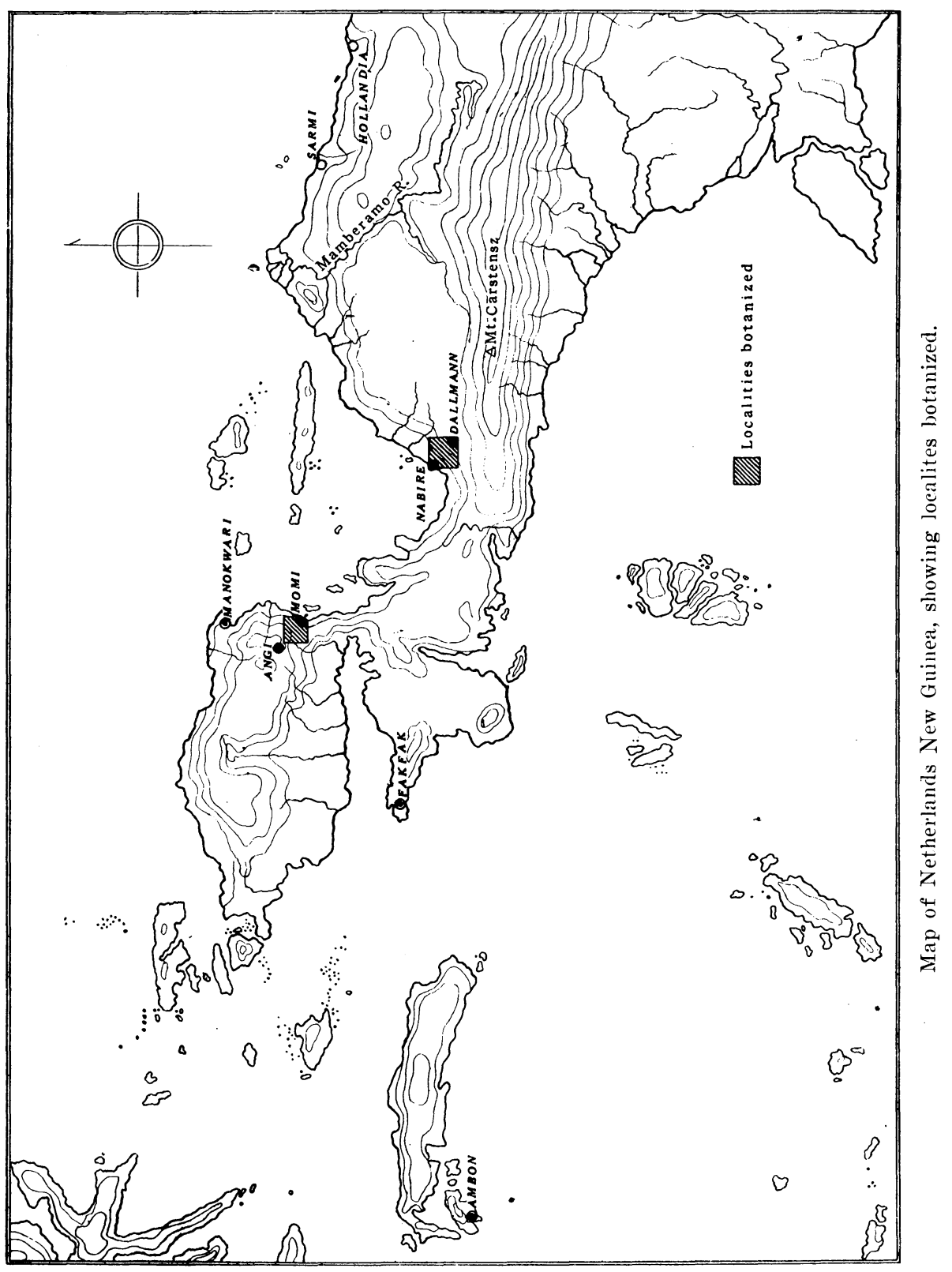




\begin{tabular}{|c|c|c|c|c|c|}
\hline & & & Woody & Herbaceous & Total \\
\hline \multicolumn{3}{|c|}{ Pteridophytes } & 11 & 300 & 311 \\
\hline \multirow{3}{*}{ Dicotyledons } & \multicolumn{2}{|c|}{ Gymnosperms } & 14 & - & 14 \\
\hline & \multirow{2}{*}{ Angiosperms } & Polypetal & 753 & 66 & 819 \\
\hline & & Gamopetal & 383 & 77 & 440 \\
\hline \multicolumn{3}{|c|}{ Monocotyledons } & 82 & 339 & 421 \\
\hline \multicolumn{3}{|c|}{ Total species } & 1,223 & 782 & 2,005 \\
\hline
\end{tabular}

Pteridophyta; Dr. S. Kitamura, Compositae; Dr. T. Tuyama, Orchidaceae ; and Dr. J. OHwi, Cyperaceae and Gramineae. We are under obligations to the government authorities of the Netherlands East Indies in granting us permission to undertake the field work and for assistance and courtesies shown to us during the time that we were in the Archipelago.

\section{PANDANACEAE* \\ Freycinetia GaUdichaUd}

\section{§ Oligostigma.}

(1) Freycinetia angustissima RIDLEy Journ. Bot. 24 (1886) 359; MARtelli Webbia 3 (1910) 309; Merr. et Perry Journ. Arnold Arb. 21 (1940) 163.

Freycinetia stenophylla Warbg. in K. Schum. et Lauterb. Fl. Deutsch. Schutzgeb. Südsee Nachtr. (1905) 53; Martelli Webbia 3 (1910) 315, Journ. Arnold Arb. 10 (1929) 137; White ibid. 201; Merr. et Perry ibid. 20 (1939) 141.

Freycinetia polyclada Merr. et Perry Journ. Arnold Arb. 20 (1931) 141.

No. 12792 Kanehira-Hatusima, between Boemi and Prau, about $40 \mathrm{~km}$. inland from Geelvink Bay, March 11, 1940. Along a trail, at about $300 \mathrm{~m}$. altitude.

The plant sprouts many branches, climbs the tree trunk forming a bush. The trigonous branchlets, very small leaves and globose fruit heads are the characteristics of the species.

Distrib. Widely spread in New Guinea.

(2) Freycinetia Beccarii Solms-Laubach, Ann. Jard. Bot. Buitenz. 3

* For assistance in the identification of the family, I am greatly indebted to Dr. F. D. Merrill and Dr. L. M. Perry of the Arnold Arboretum. 
(1883) 100 ; F. Mueller, Notes Papuan Pl. 2 (1890) 68; Warbg. Pflanzenr. 3 (IV, 9) (1900) 30; Martelli Webbia 3 (1910) 309; Rendle in Gibbs, Contr. Phytog. Fl. Arfak Mts. (1917) 198; Martelli, Journ. Arnold Arb. 10 (1929) 137; White ibid. 201 ; Merr. et Perry ibid. 20 (1939) 142.

No. 11752 Kanehira-Hatusima, Nabire, Feb. 27, 1940. In thickets at low altitutes.

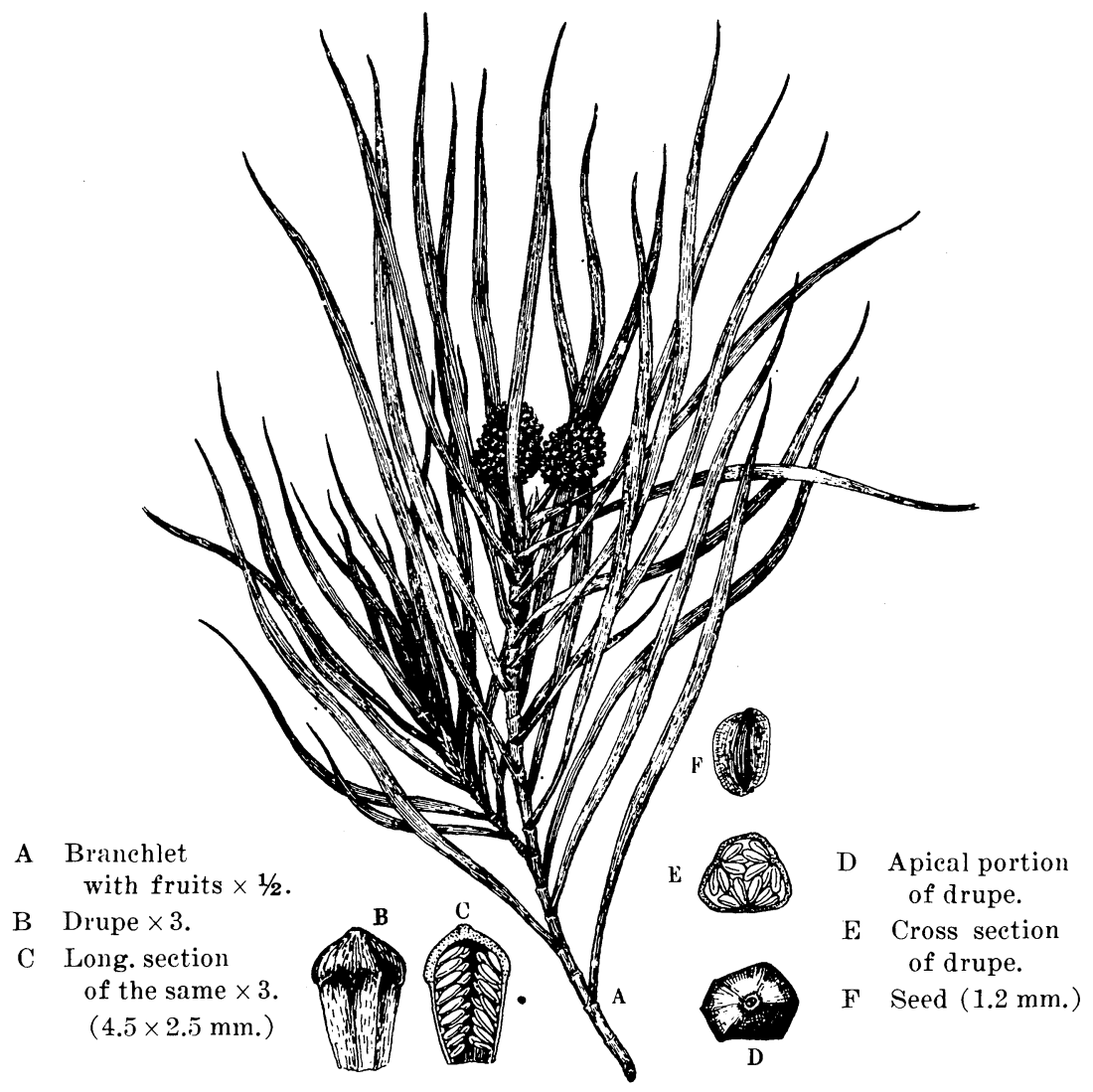

Fig. 1. Freycinetia angustissima RIDL.

Though sterile specimen, it is a striking species. A very small elimber, leaves membranaceous, smooth, 3-4 cm. long, 5-10 mm. wide.

Distrib. Known also from British New Guinea.

(3) Freycinetia cruciger Kanehira, sp. nov. §Oligostigma. Fig. 2.

Totus caulis foliaceus; ramulis $3-5 \mathrm{~mm}$. crassis, internodiis $5-7 \mathrm{~mm}$. longis, ad nodos multo radicantes, foliis dissitis, oblongo-ovatis, coriaceis, 5-6 cm. longis, amplexicaulibus, basi $1.5 \mathrm{~cm}$. latis, apice acuminatis, acumne acute mucronato, margine revolutis, margine et costa subtus minute-brevi- 
terque incerte spinulosis, longitudinaliter prominente venoso-striatis, auriculis haud liberis, $5 \mathrm{~mm}$. longis, margine pectinatis, pectinibus 2-lobatis, spathis foliis similis sed late triangularibus, margine sparse pectinatis. Infructescentiis axillaribus, pedunculo communi $4 \mathrm{~mm}$. diametro, syncarpiis globosis, $1.6 \mathrm{~cm}$. diametro, pedunculatis, pedunculo 7 mm. longo, laevi; baceis succulentis, fusiformibus, 8 mm. longis, $3 \mathrm{~mm}$. crassis, angulatis, apice acute pyramidatis, basi confluentibus, stigmatibus 3 , annulo angusto cinctis, seminibus 3 -seriate dispositis, oblongis, circiter $1 \mathrm{~mm}$. longis, vulgo rectis, raphe raphidophora, strophiolo nullo.

No. 12286 KaneHiraHatusima, Dallmann, March 3, 1940. In opencut forests at about $600 \mathrm{~m}$. altitude.

The plant is provided with leaves throughout the stem, and numerous roots sprouting from the nodes, the stem and leaves closely attach to the trunk of the

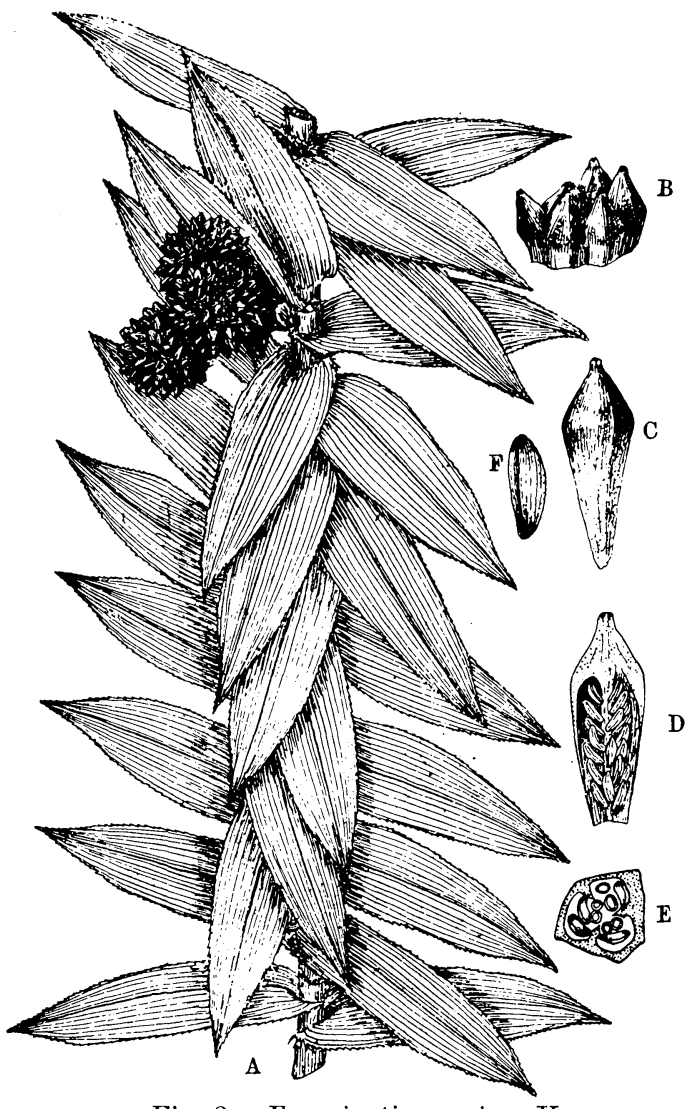

Fig. 2. Freycinetia cruciger KaneH.

A Branchlet with fruits $\times 1 / 2$.

B Upper part of the drupes $\times 1.5$.

C Drupe $\times 2.5$.

D Long. section of the same $(8 \times 3 \mathrm{~mm})$.

E Cross section of the same.

F $\quad$ Seed $\times 9$.

tree from its foot straight upward. The leaves are somewhat grayish green and expanded flatly, the two leaves on both sides of the stem and the middle one lying in cross way. We saw many sterile plants in the forests but the fruiting seems to be very seldom and we could got only one specimen. The fruits are succulent. This is a very characteristic species.

(4) Freycinetia Hollrungii Warbg. Pflanzenr. 3 (IV, 9) (1900) 30 et K. Schum. \& Lauterb. Fl. Deutsch. Schutzgeb. Südsee (1900) 161 ; Martelli Webbia 3 (1910) 311; Merr. et Perry Journ. Arnold Arb. 20 (1939) 145. 


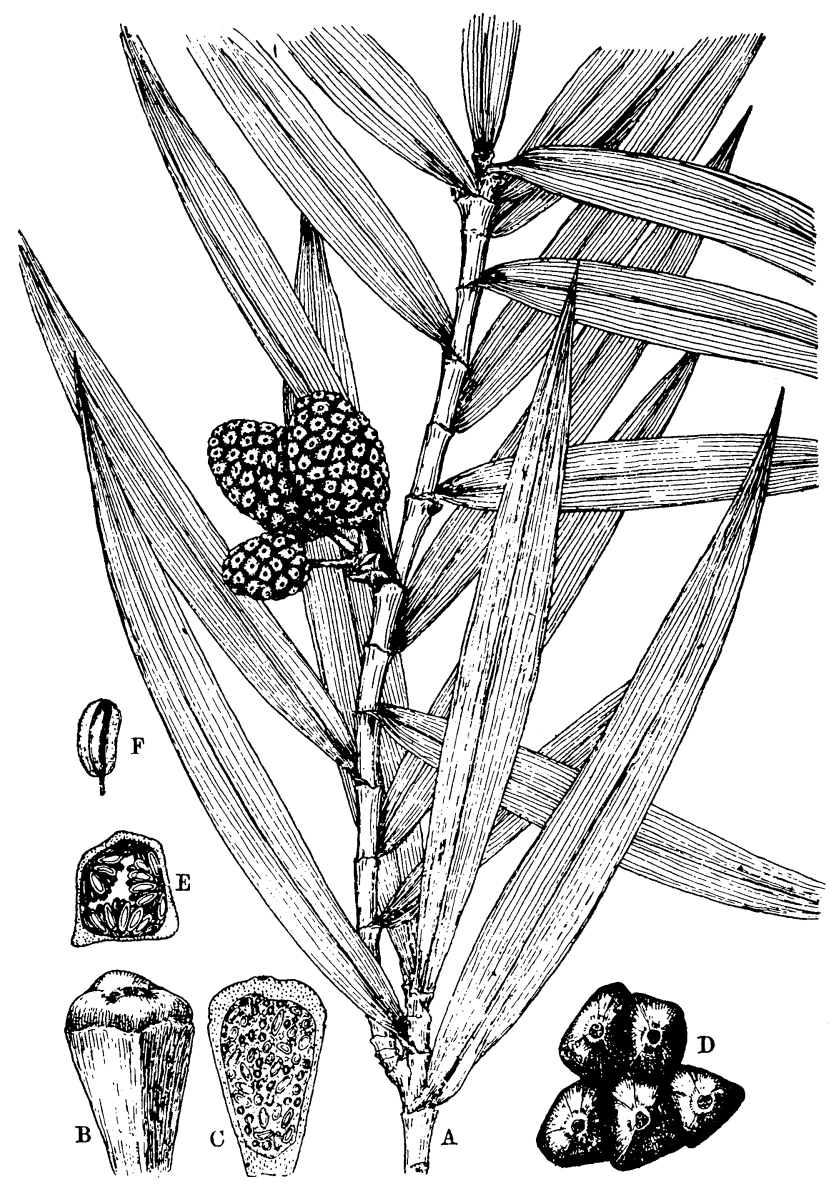

Fig. 3. Freycinetia Hollrungii WARBG.
A Branchlet with fruits $\times 1 / 2$.
$\mathrm{D}$ Apical view of the drupes $\times 2.5$.
B Drupe $\times 3(6 \times 4 \mathrm{~mm}$. $)$.
$\mathrm{E}$ Cross section of the same.
C Long. section of the same.
F $\quad$ Seed $\times 8(1 \mathrm{~mm}$. $)$.

Nos. 12202, 12260 Kánehira-Hatusima, Dallmann, March 3, $1940 . \quad$ In primary forests at about $600 \mathrm{~m}$. altitude.

The plant is quite identical with the specimen sent from the Arnold Arbonetum, assigned to Freycinetia Hollrungii. Infructescence sometimes lateral.

Distrib. Known only from New Guinea.

(5) Freycinetia Inouei Kanehira sp. nov. §Oligostigma. Fig. 4.

Caulibus teretibus, $2-3 \mathrm{~cm}$. crassis ; foliis confertis, erecto-ascendentibus, rigidiuscule coriaceis, $45-60 \mathrm{~cm}$. longis, $\pm 2.5 \mathrm{~cm}$. latis, apice acuminatis, basi plus-minusve dilatatis et acute plicatis, vaginantibus, longitudinaliter 
venoso-striatis, subtus perspicue tessellatis, margine supra basim per spatium breve denticulatis, versus apicem minutissime denticulatis, costa media subtus in parte superiore minute spinulosa; auriculis fragilibus, integris, $10-13 \mathrm{~cm}$. longis, $2 \mathrm{~cm}$. latis, haud liberis. Infructescentiis terminalibus, pedunculo communi tereti, laevi, syncarpiis 3 , cylindraceis, $10 \mathrm{~cm}$. longis, $3 \mathrm{~cm}$. diametro, pedunculis angulis, $6 \mathrm{~cm}$. longis, laevibus, baccis succulentis, confertis, linearibus, $12 \mathrm{~mm}$. longis, in sicco 2-3 mm. crassis, stigmatibus vulgo 2 , annulo angusto cinctis, seminibus fusiformibus, utrinque angustatis, $1.2 \mathrm{~mm}$. longis, raphe erassa, raphidophora, strophiolo nullo.

No. 12163 Kaneh́ira-Hatusima, Dallmann, March, 2, 1940. Climbing on a tall tree in forests at about $700 \mathrm{~m}$. altitude.

The leaves are rigid, erect and straight, and tinged with purple colour when fresh. 'The syncarp splits transversely when dried. No doubt, this is very close to Freycinetia Archboldiana Merr. et Perry, but in comparing with the type, I found my species has much thicker syncarp with much more slender and numerous drupes. It is named after Mr. Yosio Inoue of Nanyô Kôhatu Kaisya who took charge of us, while

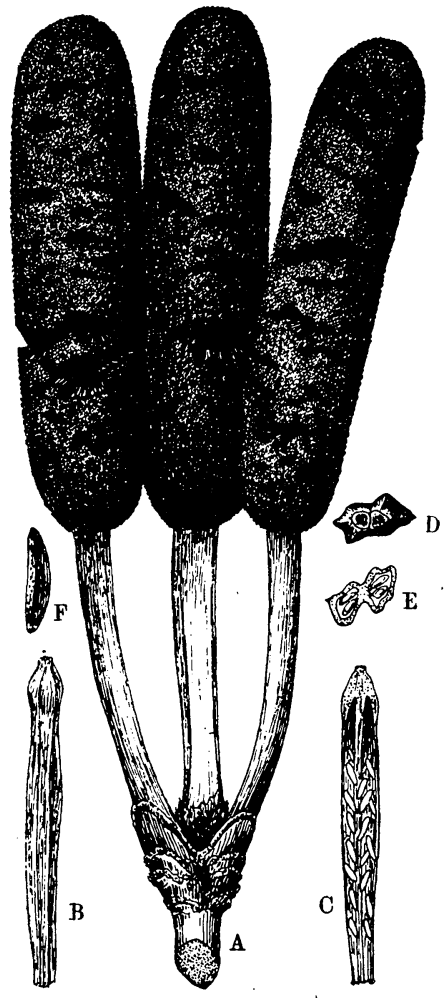

Fig. 4. Freycinetia Inouei KANEH.

A Infructescence $\times 1 / 2$.

B Drupe $\times 8(12 \times 2.5 \mathrm{~mm}$. $)$.

C Long. section of the same.

D Apical portion of drupe.

E Cross section of the same.

F $\quad$ Seed $\times 9(1.2 \mathrm{~mm}$. $)$. we botanized in Nabire. He also found and collected many plants for us in our journey.

(6) Freycinetia Klossii Ridley Trans. Limn. Soc. 2 Bot. 9 (1916) 236 ; Merr. et Perry Journ. Arnold Arb. 20 (1940) 146.

No. 12053 Kanehira-Hatusima, Dallmann, March 1, 1940 ; Nos. 12161, 12162, 12200 Dallmann, March 2, 1940 ; Nos. 12201, 12262, Dallmann, March 3, 1940. No. 12508 Kanehira-Hatusima, Sennen, Boemi, March 6, 1940.

The species is very common in Nabire District. Leaves imbricate, linear, 30-40 cm. long, $1.5-2 \mathrm{~cm}$. wide, margin minutely serrate except the middle part, auricles membranaceous, up to $5 \mathrm{~cm}$. long; syncarps usually 3 , globose, $2-3 \mathrm{~cm}$. long, somewhat succulent, scarlet when ripe, strophiole of 
the seeds lacking.

Distrib. Also known from British New Guinea.

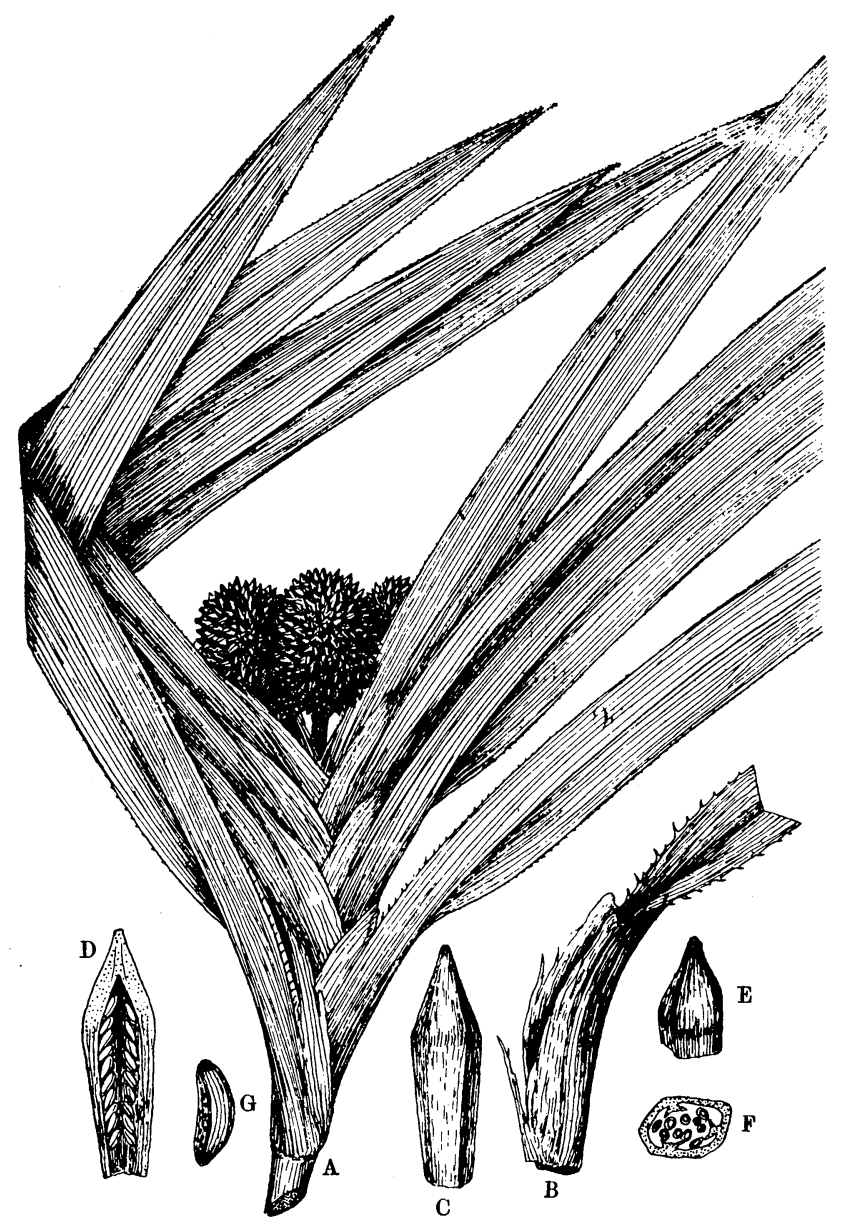

Fig. 5. Freycinetia Klossii RIDL.

A Branchlet with fruits $\times 1 / 2$. E Apical portion of drupe.

B Basal part of leaf. $\quad F$ Cross section of the same.

C Drupe $\times 3(9 \times 2.5 \mathrm{~mm}$. $) \quad$ G Seed $(1.5 \mathrm{~mm}$. $)$.

D Long. section of the same.

(7) Freycinetia lacinulata Kanehira sp. nov. §Oligostigma. Fig. 6. Caulibus \pm trigonis, $5-6 \mathrm{~mm}$. crassis, internodiis $1.5 \mathrm{~cm}$. longis ; foliis dissitis, patentibus, submembranacèis, linearibus, $20-25 \mathrm{~cm}$. longis, $1.5 \mathrm{~cm}$. latis, apice sensim attenuato-acuminatis, basi angustatis, subamplexicaulibus, in parte apicali minutissime spinoso-denticulatis, caeterum laevibus, utrinque longitudinaliter venoso-striatis, auriculis $2-2.5 \mathrm{~cm}$. longis, laci- 
nulatis. Infructescentiis terminalibus, syncarpiis 2 vel 3 , ellipsoideis, 20 $\mathrm{mm}$. longis, pedunculatis, pedunculis $1.5 \mathrm{~cm}$. longis, laevibus ; baccis prismaticis, $4.5 \mathrm{~mm}$. longis, $2 \mathrm{~mm}$. erassis, apice rotundatis vel subtruncatis, stigmatibus 2 vel 3, annulo laevi, seminibus fusiformibus, utrinque angustatis, vix $1 \mathrm{~mm}$. longis, raphe raphidophora, strophiolo nullo.

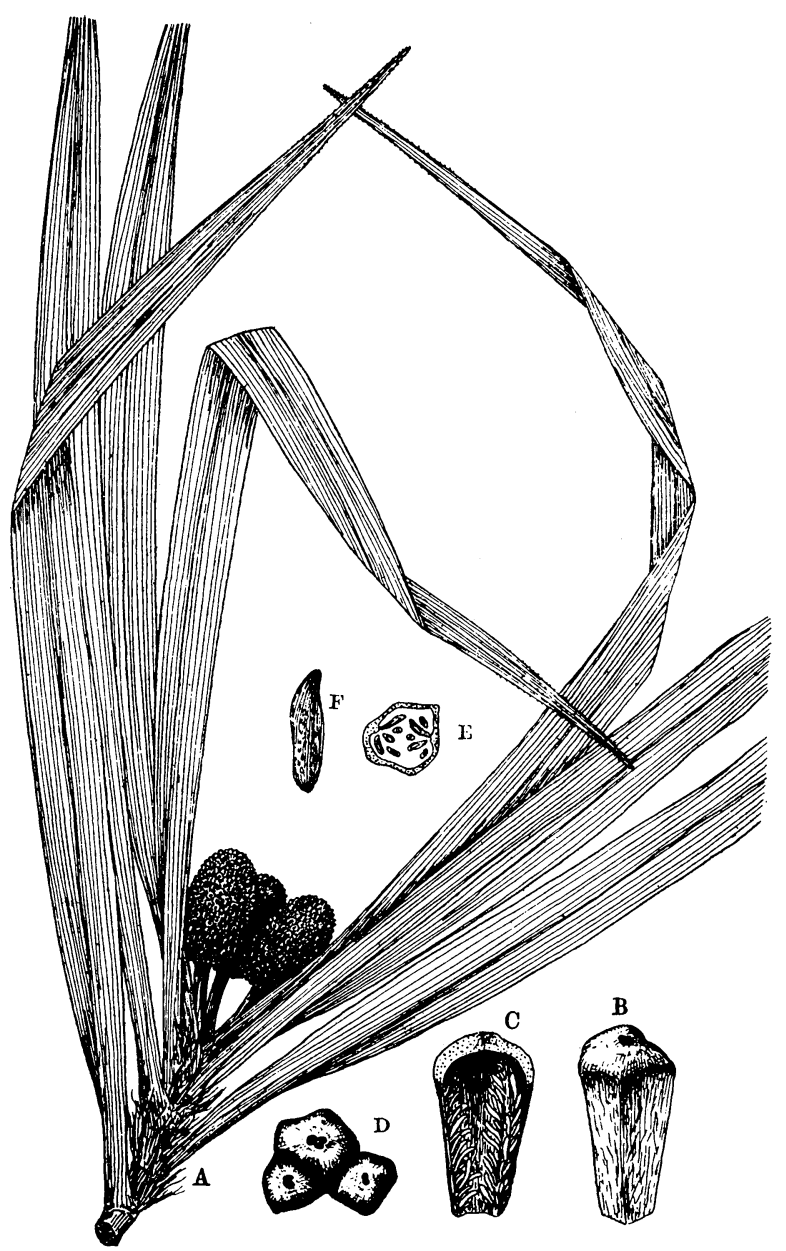

Fig. 6: Freycinetia lacinulata KANEH.
A Branchlet with fruits.
D Cross section of the same.
B Drupe $\times 4(4.5 \times 2 \mathrm{~mm}$. $)$. E Apical portion of drupes $\times 5$.
C Long. section of the same. F Seed (1 mm.).

No. 12054, Kanehira-Hatusima, Dallmann, March 1, 1940; No. 12157 Kanehira-Hatusima, the same locality, March 2, 1940.

Yellowish green leaves when dried, thread-like auricles and bright yellowish ellipsoid syncarps with nearly truncate apex of the drupes are 
the distinguished characters of the species. The present species is very closely allied to Freycinetia Brassii Merr. et Perry from British New Guinea, but the syncarps of the latter is oblong to cylindrical, brown to orange-red coloured.

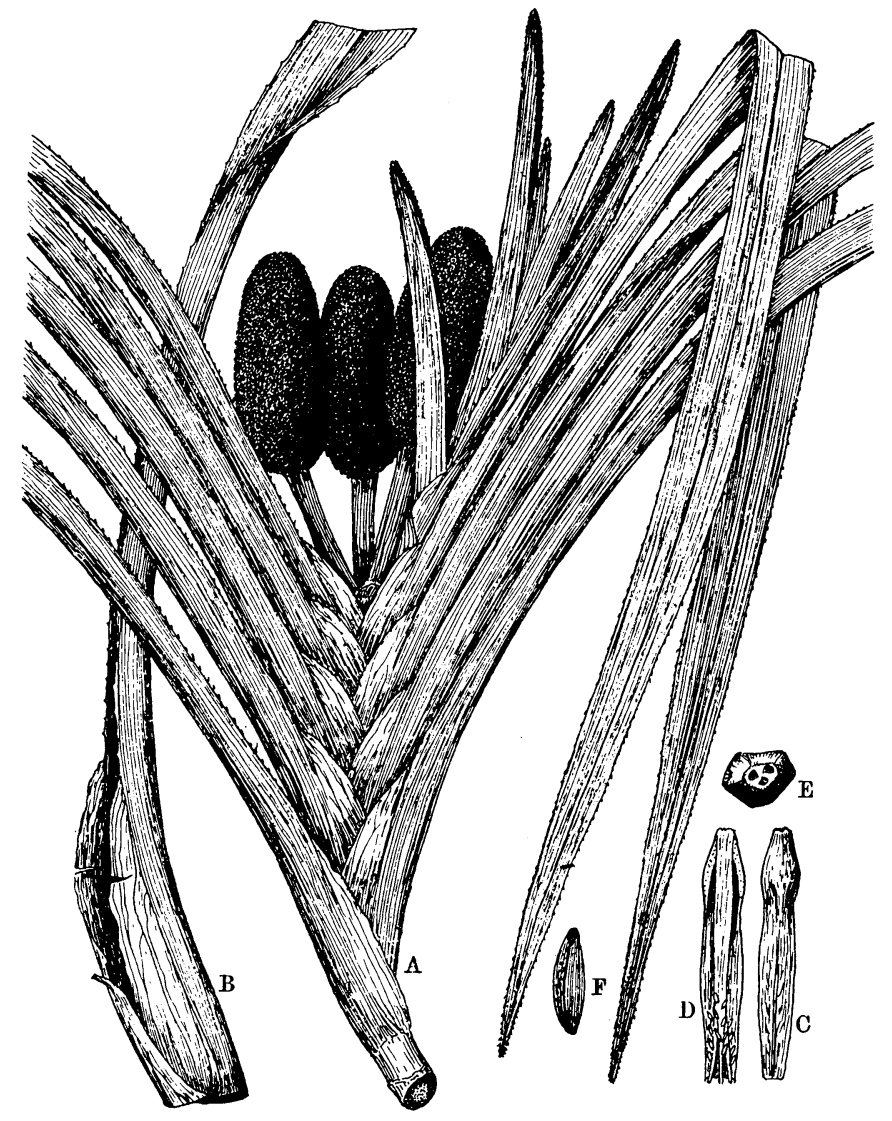

Fig. 7. Freycinetia latiauriculata KANEH.

A Branchlet with fruits $\times 1 / 2$. D Long. section of the same.

$B$ Basal portion of leaf. $\quad \mathrm{E}$ Apical view of drupe $\times 8$.

C Drupe $\times 4(6 \times 1.2 \mathrm{~mm}$. $) . \quad$ F Seed $(0.6 \mathrm{~mm}$. $)$ (immatured).

(8) Freycinetia latiauriculata Kanehira sp. nov. §Oligostigma. Fig. 7. Caulibus foliaceis, $8-10 \mathrm{~mm}$. crassis, internodiis $1.5 \mathrm{~cm}$. longis ; foliis confertis, imbricatis, subcoriaceis, 40-60 cm. longis, circiter $2 \mathrm{~cm}$. latis, apice sensim acuminatis, \pm recurvatis, basi vaginantibus, supra valde, subtus longitudinaliter venoso-striatis, obscure tessellatis, margine toto et costa supra media subtus breve remotiusculeque spinoso-denticulatis; auriculis late lanceolatis, usque ad $6 \mathrm{~cm}$. longis, $1 \mathrm{~cm}$. latis, scarioso-membranaceis, adnatis. Infructescentiis terminalibus, syncarpiis cylindraceis vel oblongo- 
cylinraceis, 4-5 cm. longis, $1.5-2 \mathrm{~cm}$. diametro, pedunculatis, pedunculis $3 \mathrm{~cm}$. longis, laevibus; baccis (immaturis) lineariformibus, $6 \mathrm{~mm}$. longis $2 \mathrm{~mm}$. crassis, apice acutis, stigmatibus $1-3$ (vulgo 3), annulo anguste cinctis, seminibus vix $0.6 \mathrm{~mm}$. longis, raphe crassa, raphidophora, strophiolo nullo.

No. 12287 KanehiraHatusima Patema, about 40 $\mathrm{km}$. from the shore, March 4, 1940. In forest edge at about $600 \mathrm{~m}$. altitude.

The plant is characterized by very broad entire auricles.

\section{(9) Freycinetia linearis}

Merr. et Perry Journ. Arnold Arb. 21 (1940) 164.

No. 13972 KanehiraHatusima, Iray, Angi-Lake, April 8, 1940. In dense primary forests at about 2,000 m. altitude.

Scandent plant, covering the trunk of a tree; leaves linear, rigidly coriaceous, 20$30 \mathrm{~cm}$. long, 4-5 $\mathrm{mm}$. wide, strongly vaginant at the base, auricles 3-4 cm. long, 4-5 mm. wide; syncarps oblong, $3 \mathrm{~cm}$. long, $1 \mathrm{~cm}$. in diameter, upper part of the peduncle scabrid.

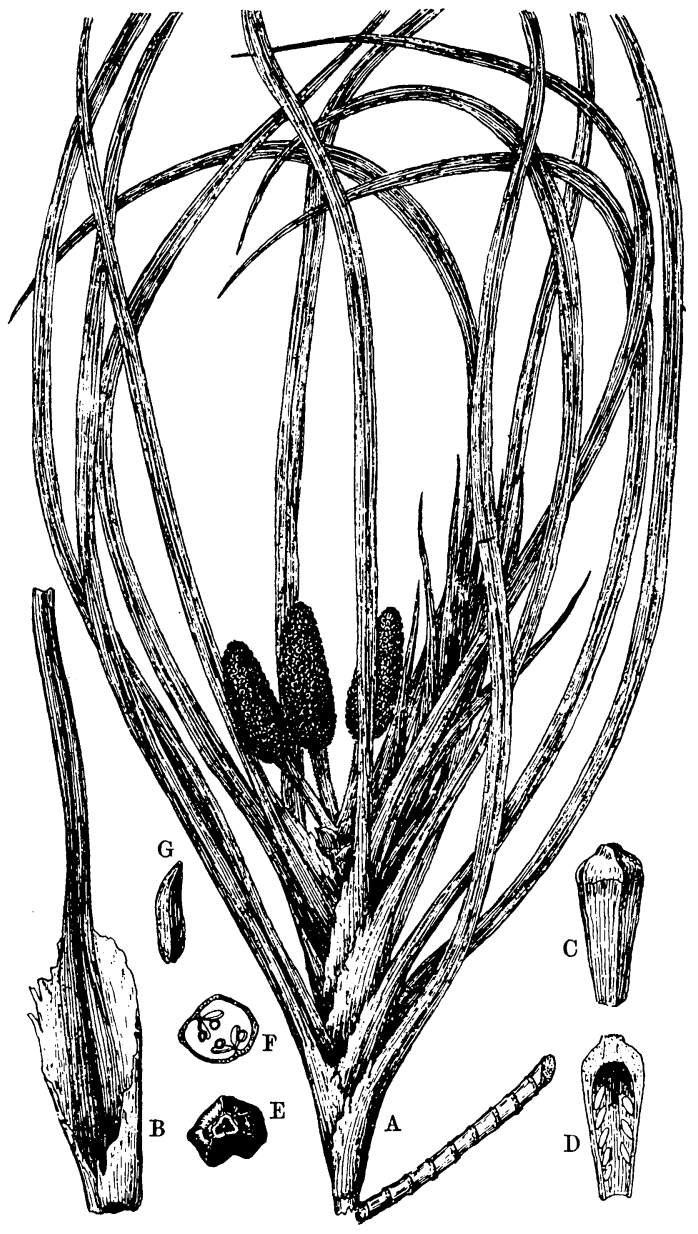

Fig. 8. Freycinetia linearis MERr. et PERRY.
A Branchlet with fruits.
B Basal portion of leaf. E Apical view of drupe. $\times 1 / 2$.
C Drupe $(4 \times 1 \mathrm{~mm}$.).
D Long. section of the G Seed $\times 10(1 \mathrm{~mm}$. $)$

The type form $12 \mathrm{~km}$. northeast of Lake Habbema at $2,600 \mathrm{~m}$. altitude. Distrib. New Guinea.

(10) Freycinetia oblanceolata Martelli, Webbia 3 (1910) 176, 313 ; Rendle in Gibbs, Contr. Phytog. Fl. Arfak Mts. (1917) 197 ; Merr. et Perry Journ. Arnold Arb. 20 (1939) 144.

Nos. 12681, 12684 (fr.) Kanehira-Hatusima, Slieber-Boemi, March 9, 
1940, in thin open forests. No. 12570 (o flos) Kanehira-Hatusima Sennen, March 7, 1940, in forests near Boemi River. No. 14113 (fr. immat.) Kanehira-Hahusima, North-Pole, Angi-Gita, April 10, 1940, in forests near the Lake at about $2,000 \mathrm{~m}$. altitude.

Scandent; leaves coriaceous, scattered, lanceolate to oblanceolate, 15$18 \mathrm{~cm}$. long, up to $4 \mathrm{~cm}$. wide, apex obtuse or obtusely apiculate, entire except the apex, auricles membranaceous, caducous. Syncarps 3 or 4 , oblong to ovoid, $5 \mathrm{~cm}$. long, $2-2.5 \mathrm{~cm}$. in diameter, often falcate, peduncles smooth, stigma 1-3, seeds $1.2 \mathrm{~mm}$. long, raphe with raphides, strophiole lacking.

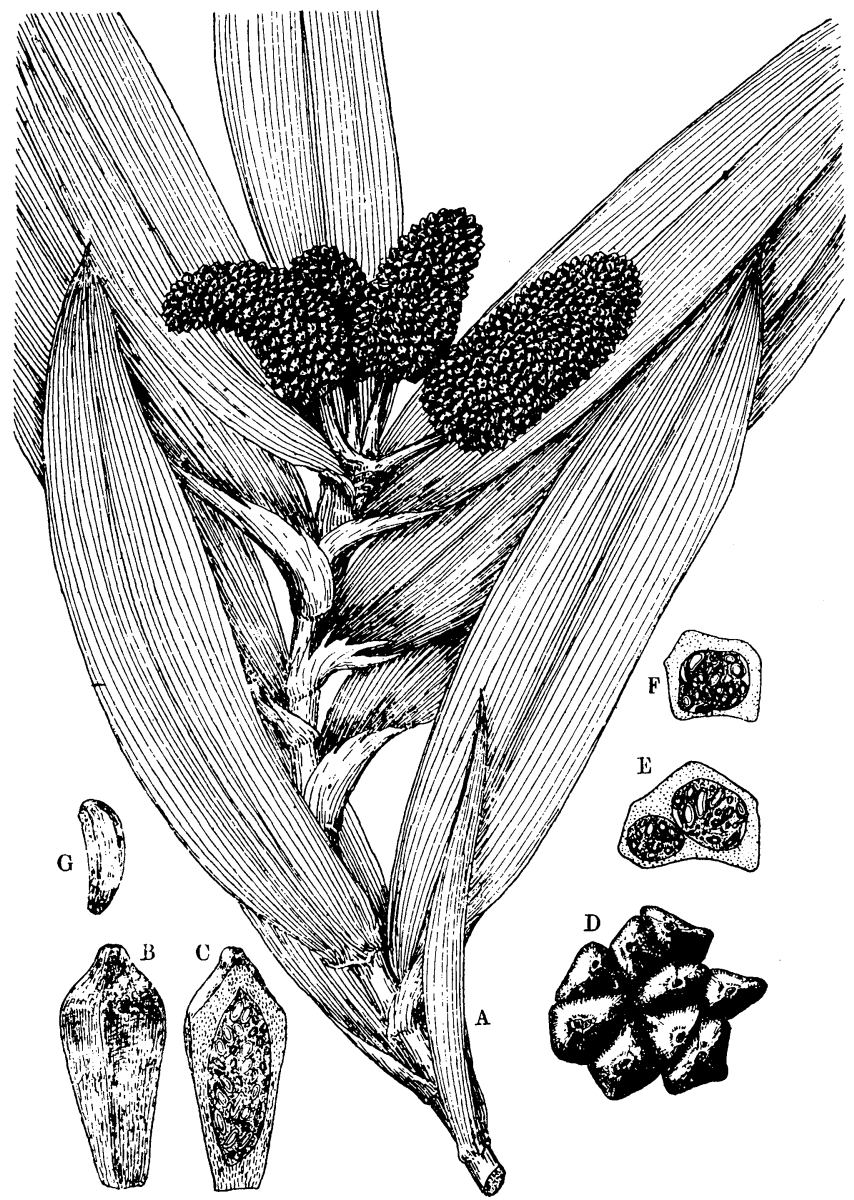

Fig. 9. - Freycinetia oblanceolata Martelli.

A Branchlet with fruits $\times 1 / 2$.

B Drupe $\times 3(8 \times 3 \mathrm{~mm}$. $)$.

C Long. section of the same $\times 3$.
D Apical view of drupes $\times 2.5$.

$\mathrm{E}, \mathrm{F}$ Cross section of the drupe $\times 4$.

G Seed. 
Distrib. Known also from British New Guinea.

(11) Freycinetia platyphylla Kanehira sp. nov. §Oligostigma. Fig. 10. Scandens ; caulibus $\pm 2 \mathrm{~cm}$. crassis ; foliis crasse coriaceis, in apicem ramulorum confertis, lomariformibus, $120 \mathrm{~cm}$. longis, ad basim 7-8 cm. latis, apicem versus abrupte attenuatis, basi breviter vaginantibus, longitudinaliter conspicue venosis, in sicco perspicue tessellatis, marginibus in partibus basilaribus et in apicibus breviter minuteque spinoso-denticulatis, caeterum remotiuscule denticulatis, costa media subtus in parte superiore sparse denticulata; auriculis usque ad $10 \mathrm{~cm}$. longis, haud liberis. Infructescentiis terminalibus, pedunculo communi \pm trigono, $1.2 \mathrm{~cm}$. crasso, laevi, syncarpiis ternis, cylindraceis, 10-12 cm. longis, $3-3.5 \mathrm{~cm}$. latis, pedunculis $5-6 \mathrm{~cm}$. longis, angulatis, laevibus; baccis succulentis, numerosissimus, confertis, linearibus, 10-12 mm. longis, in siceo vix $1 \mathrm{~mm}$. latis, angulatis, apicem versus angustatis, stigmatibus plerumque 2, annulo angusto cinctis, seminibus immaturis.

No. 12285 Kanehira-Hatusima, Dallmann-Patema, March 4, 1940. In forests at about $600 \mathrm{~m}$. altitude.

This is very near Freycinetia tessellata Merr. et Perry, but is

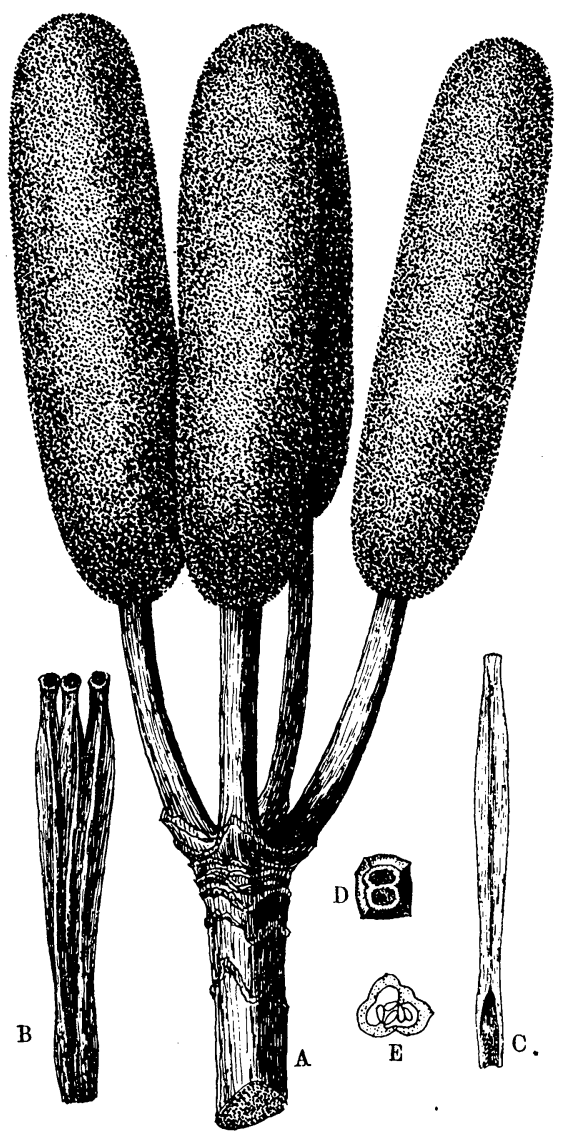

Fig. 10. Freycinetia platyphylla KANEH.

A Infructescence.

B 'Drupes $\times 3.5$.

C Long. section of the same. - (10-12 mm.).

D Apical view of drupe $\times 10$.

$\mathrm{E}$ Cross section of the same.

distinguished by its glabrous peduncles; it is also near Freycinetia ponapensis MARTELLI but is separable by the rather obtuse tips of the leaves and the much longer syncarps.

(12) Freycinetia rectangularis KaneHira sp. nov. §Oligostigma. Fig. 11. Rami tereti, $7 \mathrm{~mm}$. crassi, internodiis $1.8 \mathrm{~cm}$. longis, ad nodos spinis praeditis, spinis conoideis, $2 \mathrm{~mm}$. longis, ramulis frugiferis inermibus, foliis 
dissitis, patulis, lanceolatis, membranaceis, $6-8 \mathrm{~cm}$. longis, $1.6-2.0 \mathrm{~cm}$. latis, utrinque subacutis, abruptiuscule in acumen brevem abeuntibus, nervis parallelis, prominentibus, margine fere laevibus, apice tantum minutissime spinulosis, auriculis probabiliter caducis. Infructescentiis terminalibus, syncarpiis 2 , ellipsoideis, $2 \mathrm{~cm}$. longis, $1.4 \mathrm{~cm}$. crassis, pedunculatis, pedunculis $2.2 \mathrm{~cm}$. longis, laevibus, baccis cylindraceis, $4 \mathrm{~mm}$. longis, $2 \mathrm{~mm}$. latis, apice rotundatis, vertice foveolatis, stigmatibus 2 vel 3 , saepius 4 , seminibus vix $0.5 \mathrm{~mm}$. longis, raphe inconspicua, strophiolo nullo.

No. 12383 Kanehira-Hatusima, Semnen, Nabire, March 6, 1940 . In primary forests at low altitudes.

A small climber, stem armed with spines, young fruiting branchlets

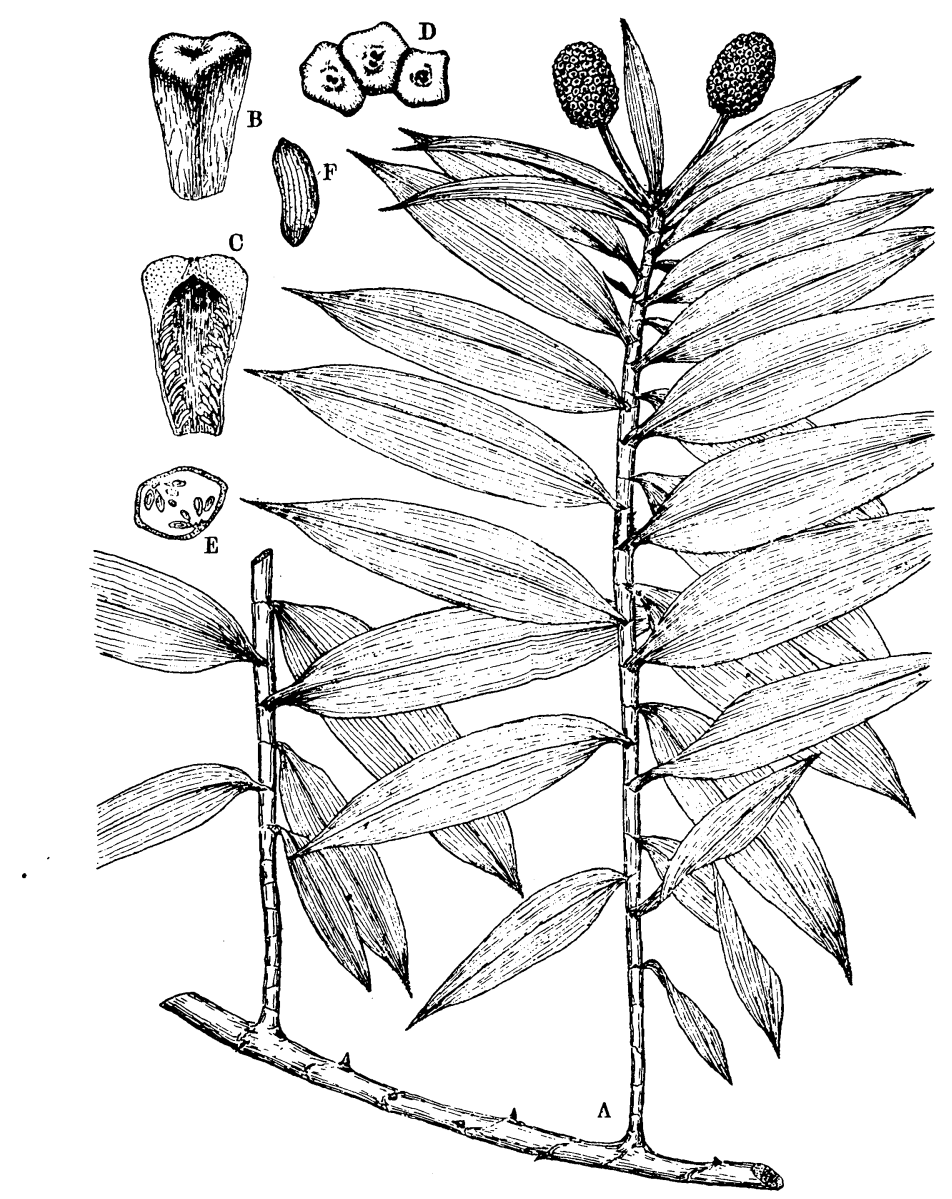

Fig. 11. Freycinetia rectangularis $\mathrm{KANEH}$.

A Branchlet with fruits $\times 1 / 2$. C Long. section of the same. E Cross section of drupe.

B Drupe $\times 4.5(4 \times 2 \mathrm{~mm}$.). D Apical view of the drupes. $F$ Seed $(0.5 \mathrm{~mm}$. $)$. 
sprouting perpendicularly to the stem, leaves lanceolate, membranaceous, parallel nerves prominent, syncarps yellowish, nearlv smooth on the surface.

(13) Freycinetia spinellosa Kaneinra sp. nov. §Oligostigma. Fig. 12. Ramulis teretibus, 4-7 cm. crassis, internodiis circ. $10 \mathrm{~cm}$. longis ; foliis, coriaceis, imbricatis, \pm erecto-ascendentibus, linearibus, usque ad $50 \mathrm{~cm}$. longis, $0.8 \mathrm{~cm}$. latis, sursum acuminatis, basi paullo angustatis, vaginantibus. utrinque longitudinaliter venoso-striatis, apice remotiuscule spinulosis. in parte media fere laevibus, basi supra auriculis denticulatis; auriculis late

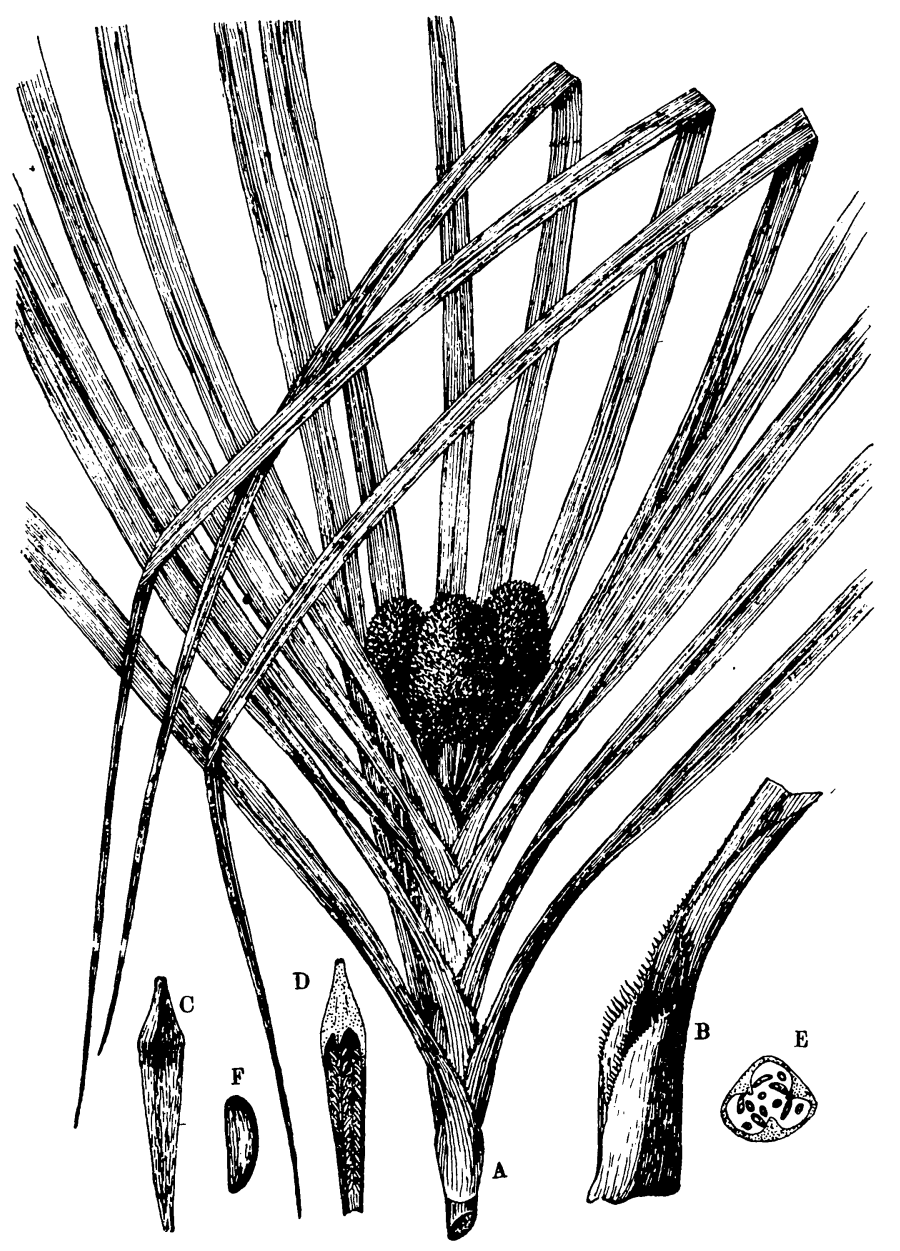

Fig. 12. Freycinetia spinellosa KANEH.
A Branchlet with fruits $\times 1 / 2$.
D Longitudinal section of the same $\times 2.5$.
B Basal part of leaf.
E Cross section of the same (magn.)
C Drupe $\times 2.5$.
F seed (1 mm. long). 
lanceolatis, $2.5 \mathrm{~cm}$. longis, 4-5 mm. latis, margine pectinatis, membranaceoscariosis, in fibras cito solutis. Infructescentiis terminalibus, syncarpiis 3, oblongis vel ovoideis, $3 \mathrm{~cm}$. longis, $\pm 2 \mathrm{~cm}$. diametro, pedunculatis, peduneulis seabridis, praecipue in angulis, baccis fusiformibus, $7 \mathrm{~mm}$. longis, $1.5 \mathrm{~cm}$. crassis, basi haud liberis, apice anguste pyramidatis, stigmatibus 1 vel interdum usque ad 4, annulo angusto cinctis, seminibus vix $1 \mathrm{~mm}$. longis, raphe crassa, strophiolo nullo.

No. 12052 Kanehira-Hatusima, Dallmann, March 1, 1940. No. 12507 (type) Kanehira-Hatusima, Sennen, Boemi River, March 7, 1940. No. 12791 Kanehira-Hatusima, Boemi-Prau, March 11, 1940. No. 13089 Kanehira-Hatusima, Momi, along the seashore, March 23, 1940.

The species is characterized by its very long slender leaves and broad lanceolate auricles with pectinate margin.

(To be continued).

\section{金平・初島探集ニニーギニヤ植物研究 I (和交摘要)}

金 本 亮 三

はしがき

昭和 15 年私八蘭領ニユーギニヤニ植物ヨ探集スル機會ガ與ヘラレ初島住彥君 帶同シ 1 月 18 日，日本 7 出發，一路爪哇二渡リ同地ノ植物學者二面會シ文獻 7 借覽, 且ツニスーギニヤ探檢ノ援助卜便宜卜ヨ當路ノ人二依賴シ夕。2月10 日スラバヤ 出帆，12 日セレベス島 マカツサー着，ニユーギニヤ行／便船二移乘，2月 20 日マ ヌコワリ 到着, 更ニナビレ二至り南洋興發會社ノ假小屋二初メテ日本カラノ旅裝 ヨ解キ探集ノ準備ヨシタ。

ニユーギニヤ二於ケル第 1 包ノ探集地ハナビレノ南方, 山奧凡 $40 \mathrm{~km}$. ダマル探集 地ヨ中心トシタル地方トソノ往複ノ沿道森林地帶デアリ, 第 2 包ハマヌコワリノ南 方へールフインク灣二沿フ南洋興發ノモミ農場附近ノ森林地帶, 第3 包八モミノ西 方, 海拢 $2,000 \mathrm{~m}$ ノ地ニアルアンギ湖畔トソノ地二到儿往復沿道地帶デアツタ。コ ノアンギ湖ハ 1913 年 L. S. GiBBS 女史ガ採集シ, ソノ研究ノ結果, 名著 A contribution to the phytogeography and flora of the Arfak Mountains (1917) ガ出版セラレ 夕。當時卜今日トハソノ事情モ一變シテ居ルガ女史八 330 種ノ標本 ノ論文 $=317$ 種 (ウチ 66 種八羊齿類以下) ヨ揭が 4 新屬卜 100 ノ新種ヨ゙發表シ 夕。我々ノ今包ノ探集中，ソノ收獲ノ最モ多カッタノ八實ニコノアンギ地方デソノ 探集點數八 860 デアリ，1 新屬ノ外ニアンギ地帶ノ新記錄屬 64 ，ニユーギニヤ大陸 ノ新記錄屬 4 ヨ得タノデアツタ。 
ニユーギニヤ大陸ノフロラノ研究ハソノ日ガ淺ク蘭領側八 1907-1913 年ノ大探檢 以外二見ルベキモノハナイ樣ダガ, 舊獨領側八前大戰ガ始マルマデ現地ノ調查ガ續 ケラレタ。

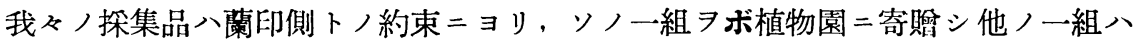
交換用トシテアーノルド樹木園二送附スルノ豫定ニナツテキル。

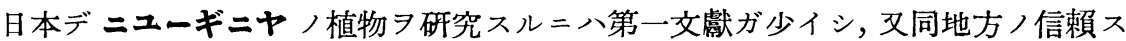
可キ標本ガ殆ド無イノデ甚ダ困難ナ事情ニアル。前記蘭印ノ探檢報告トシテ有名ナ Nova Guinea スラ日本デハソノ完本ガ無イ位デアルカラ他八推シテ知ル可シデアル。 尤モ我國唯一ノ完本デ臺灣總督府調查課所管二屬シ目下八臺北南方協會ノ圖書室二 所藏七ラレテアルノヨ借用スルコトノ出來タノ八仕合セデアツタ。

ソノ他ノ文獻モ甚ダ尠イノデアルガ，今包ノ標本二手习染メ又譯二行カヌカラ出 來ル限リ日本デ研究ヨナシ，ドウシテモ手二オへヌモノ八外國二依賴スル計畫 テ，取リ敢へズ羊药類八伊藤洋理學博士二，菊科八北村四郎博士二，蘭科八津山向 理學士二，又禾本科卜莎草科卜ハ大井次三郎博士ニソノ研究ヨ夫々依賴シタ次第デ アル。

\section{(I) タコノキ 科}

今包採集シタタコノキ科入 Freycinetia 屬入 18 種, Pandanus 屬入 14-16 種デア ツタ。タコノキ屬八先年猪熊農學士ノ探集品ガ私二提供セラレタノデ，私ハソノウ チノ新種ト共ニニューギニヤ産タコノキ 本誌二發表シタ。ソノ當時ハ 42 種, 3 變種ガ知ラレテキタガソノ後メリル・ペリーニョリ 8 新種ガ加ヘラレ 50 種トナツ 夕。コノウチ兩氏創定ノコタイプガ私ノ手元二送クラレタノデ鑑定上非常二役立ツ タ。ツルタコノキ屬ニツイテハ私八未ダニユーギニヤ産ノ全部习調查シテキナイガ メリル・ペリーノ發表シタモノダケデ 44 種アリ，コノウチ 29 種八同兩氏ノ創定 シタ新種デアル。

本科ノ標本ノ一部ハメリル博士二寄贈シタノデ，鑑定上前記兩氏ノ助言卜援助卜 ア得タコト八感謝二タヘヌ所デアル。

又本研究二當り文部省科學研究費八一部 ガソノ支途二當テラレタルコトラ茲二特記 スル。

\section{Freycinetia 屬}

(1) Freycinetia angustissima RIDLEY 八 細イ蒙二枝ガ澤川出ル，ブミ川二沿フ森林 中樹木二絡マツテ居タ。メリルハ $F$. poly(lada Merr. et Perry トシタガ, 後本種) 異名二變更シタ。

(2) Freycinetia Beccarii Solms-Lauba$\mathrm{CH}$ 八 sterile ノ標本デアルガ細イ膜質ノ葉

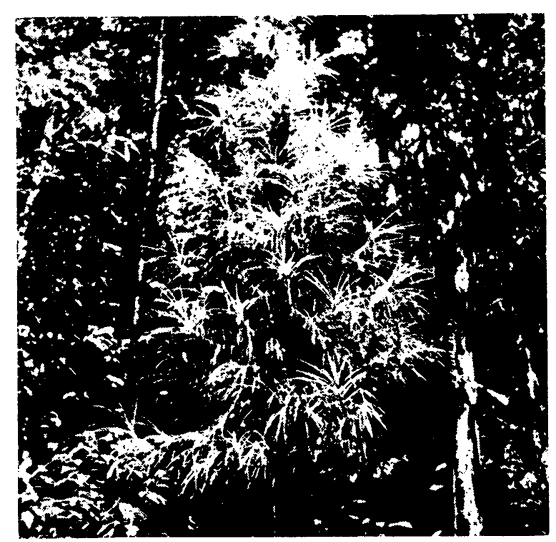

Freycinetia angustissima. 
デ長サ 3-4 cm. 幅 5-10 mm. メリルノ來信ニョルト本種二間違ハナイトイフ。

(3.) Freycinetia cruciger KANEH. 大キナ樹幹ニイツモ密着シ根え゙カラ畺直グニ 伸ビテキル，外觀 Aracea $\dot{e}=$ 似テキル，某八淡イ灰綠色デ各節每二根ヨ出シ葉 字形二密着スル，ダルマン地方二ノミ澤山見タガ實ノアルモノ八只一ツダケデア ツタ。F. ellipsoidalis Merr. et PerRy 二似テキルガ本種ノ葉八ヨリ大デアリ特色, アル種類デアル。

(4) Freycinetia Hollrungii WARB. 本種ハアーチボルド探檢デ得夕標本ニツキ メリルガ本種=同定シタ標本ト全ク合致スル，尤モメリルハW 比較ノ上, 鑑定シ夕モノナリヤ否不明ナルモ, 目下ノ處メリル,鑑定二從フョリ 外ハナイ。

(5) Freycinetia Inouei Kaneh. 一見 F. Archboldiana Merr. et Perry 二近イガ 實八ョリ大デ核果八細長ナルニョリ容易二區別ガツク。

(6) Freycinetia Klossii RIDLEY ダルマン地方二多ク，澤山ナ標本ヨ得夕、本種 ノ鑑定ニ八間違ナイ，ニユーギニヤデハ相當廣ク分布スルモノラシイ。

(7) Freycinetia lacinulata KANEH. Auricle ガ節ノ處カラ房ノ樣二分カレテ出 テ居ル。F. Brassii MERR. et PERRY 二近イガソノタイプト比較スルト本種ノ葉ハョ リ細長デアリ實八黃熟スルノデ區別スル。

(8) Freycinetia latiauriculata KANEH. 廣イ auricle ヨ有スルノガ本種ノ特長デ アル。

(9) Freycinetia linearis MerR. et PERRY 葉ノ基部ハ完全ナ鞘狀デ廣イ膜質, auricle ヨ有ツテキル, 特色アル種類デ高地帶二生ジ分布八廣イト見へル、アンギ湖 畔 $2,000 \mathrm{~m}$. ノ所デ探集シタ。

(10) Freycinetia oblanceolata MARTELLI ダルマン及ビアンギデ探集シタ，分布 ノ廣キヨ思ハシメル,メリルカラ寄贈セラレタ標本トョク一致スル。

(11) Freycinetia, platyphylla Kaneh. F. tessellata Merr. et Perry $尹$ 思ハシメ 儿種類デ，葉ハソノ幅 7-8 cm. 實ハ大キナ圓筒形シナス $=ヨ$ 區別スル。

(12) Freycinetia rectangularis KANEH. 基二刺アリ，枝八直角二出ル。

(13) Freycinetia spinellosa KANEH. Auricle =節形ノ小刺ガアルノデ區別ガ出 來ル。

(續ク) 